\title{
Unpacking policy gridlocks in Africa's development: An evolving agenda
}

Julius Mugwagwa, University College London

Geoffrey Banda, University of Edinburgh

Maurice Bolo, Scinnovent Centre

Susan Kilonzo, Maseno University

Clapperton Mavhunga, Massachusetts Institute of Technology

Vuyo Mjimba, Human Sciences Research Council

Olivia Muza, Independent Consultant

Zeferino Teka, UNDP

\begin{abstract}
Policies are not an end in themselves, but deliberate systems of principles to guide decisions and achievement of rational outcomes. Many factors inherent in or transcending policy processes have dramatic consequences for how policies are interpreted and applied. In this article, we deploy the concept of 'policy gridlocks' to better understand factors that facilitate or hinder implementation of single or multiple policies in different African policy arenas. We argue that minimizing or ameliorating 'policy gridlocks' requires stakeholders to quantify and more directly feel the cost of their decisions and actions, while scholars must continue to search for institutional means to prevent gridlocks, including broadening the array of conceptual and analytical tools for understanding policy processes. We conclude that limits in financial resources, technical expertise and legislative capacity are the more powerful drivers of policy formulation, implementation and revision gridlocks that need to be addressed, than fragmentation of stakeholder interests.
\end{abstract}




\section{Keywords}

Africa

development

policy

policy gridlocks

policy formulation

policy implementation

\section{Introduction and conceptual underpinnings}

The term 'gridlock' comes from traffic engineering, and in simple terms refers to a situation where the flow of traffic through intersecting streets is locked into immobility. For example, when vehicles cannot clear an intersection after traffic lights have changed, or when vehicles try to enter a road at full carrying capacity, a gridlock results. In this example, gridlocks are as much a function of the state and carrying capacity of the roads and the volume of traffic and its flows and ebbs at a given point in time. Mutual cooperation among drivers could give the maximum benefit (prevention of gridlock), but may not always happen because of competing desires to maximize own benefit (shortest travel time). Gridlock, viewed as both a cause and consequence of policy failure, can therefore be modelled as a type of bargaining failure between agents unwilling to compromise (Brady and Volden 1998).

Actors in other arenas agree that 'gridlock' is too good a term to leave to the engineers alone, hence the widespread use of the term now (Mansbridge and Martin 2013). Since the New York Times magazine introduced the term to non-engineers in 1980, many kinds of complete stoppages or jams are now called gridlocks. The term is used to refer to telephone gridlocks 
(overcrowded telephone lines), vocal gridlocks and legislative/government gridlocks inter alia. In policy-making, the reality of too many policies desiring to pass through constrained regulatory systems at the same time, same pace and using the same resources and channels is not uncommon. In this article, we refer to this scenario, which usually results in little or no progress in policy processes, as a 'policy gridlock'. The causes of this are numerous and operate singly or in various permanent as well as intermittent combinations or permutations, from in-fighting among policy-makers, policy failure, policy incoherence or bad policy mixes, to lack of competence in steering processes at policy development or implementation levels. This is a common occurrence in many policy jurisdictions, which reinforces the need to understand how specific policy actors navigate and unlock gridlocks. While a number of authors, not least David Mayhew's trail-blazing work Divided we Govern (2005), have looked at this issue from various perspectives, the main preoccupation has been with national-level political processes and decision-making. Looking beyond the contemporary treatment of policy gridlocks at construction levels within legislatures, this article argues for policy gridlocks to be further studied at execution and operational levels for effective policy translation and implementation, taking into consideration inclusive and sustainable development agendas in Sub-Saharan Africa (SSA). The focus on SSA is driven by the persistent development needs of the region, most prominently reduction of poverty. For example, the United Nations Environment Programme, UNEP (2016), notes that resource efficiency is a key component of sustainable development characterized by income and economic growth as well as sound environmental management. While natural resources are still abundant in many economies in the global South, other resources that include finance, human capital as well as hard and soft infrastructure remain in deficit. This dictates a need for a broader policy-driven resource-use efficiency on both the abundant and scarce resource. 
A coherent and unambiguous public policy regime is thus a prerequisite for improved resource-use efficiencies. Against this background our article pursues from conceptual and practical perspectives the causes, manifestations (e.g. as reflected in policy stability, policy stasis or inability to change or implement policy) and options for minimization or elimination of gridlocks. The article unpacks policy gridlocks within various sectors and subsectors, drawing on the authors' independent projects, and converging on a number of areas of policy interest including but not limited to the debate over the effects of fragmentation and limits in managerial, financial, technological and governance expertise and capabilities as drivers and sustainers of policy gridlocks and the need for measures to minimize or ameliorate the gridlocks. This article argues that knowing about the existence of gridlocks is as important as knowing how to measure the extent of the gridlocks, their causes and consequences. Together these diagnostic and prognostic perspectives argued herein constitute a toolkit for unlocking blockages in policy implementation.

The article poses and addresses a number of questions relating to the emergence, existence and resolution of policy gridlocks. The main question is, how do policy gridlocks emerge, what happens in this space, and what lessons can be inherited by future and allied policy processes? Two sub-questions are posed to unpack the main question: (1) what factors, behaviours and processes exacerbate policy gridlocks; and (2) how can policy gridlocks be ameliorated? The article draws on empirical evidence from the global south covering case studies on horticulture, mining, pharmaceutical production, science, technology and innovation, the environment and health. 
The rest of the article proceeds as follows: the following section unpacks the concept of policy gridlocks, followed by a brief look at the methodologies employed by the different case studies. The next section then presents, analyses and discusses the case studies through the lens of policy gridlocks. The final section advances conclusions and implications of the findings to policy scholarship and policy implementation in developing economies and globally.

\section{Gridlocks from legislature to practice}

The concept of gridlock is widely used in the analyses of current politics (Barber and McCarty 2013). Political gridlock exists when a majority of legislators want some changes in the law to occur but no corresponding change happens. Gridlock occurs when a beneficial outcome is available but the participating agents fail to agree on how to reach this outcome. For the duration of their disagreement, both sides are stuck with a less desirable outcome. Defined this way, gridlock does not necessarily mean a lack of productivity, but instead a lack of optimal agreement (Reilly 2002) and traction that could be demonstrated by the achievement of intended policy goals. The literature on contemporary political gridlock identifies two main types, depending on whether the immediate consequence of gridlock is: (1) the preservation of the status quo, or (2) the implementation of some reversion that is not the status quo. The status quo is the currently enforced policy or legislation. For example, the status quo budget is the budget from the previous fiscal year. Another possible outcome of gridlock is the reversion, which is the alternative policy or legislation to be enforced if no change to the status quo can be agreed upon. The status quo and reversion can be the same in some circumstances, but not necessarily. Thus, it should not be assumed that the status quo and the reversion are always the same. When a gridlock leads to the preservation of the status quo, it is not necessarily a normatively bad outcome. When someone decries gridlock that 
results in the preservation of the status quo, they are really attacking the status quo itself. Conversely, the resulting outcome of failing to change the status quo, the reversion, can impose negative consequences (Mansbridge and Martin 2013).

In forming and implementing policy, legislators and bureaucrats face uncertainty on a number of levels: uncertainty over the actual policy results of passing a bill, and uncertainty over constituent reactions to voting for or against a bill (Binder 1999). Always faced with some level of uncertainty, these key actors have to take many steps to minimize that uncertainty, including listening to constituents and paying attention to surveys and polls. At all levels, the normal practice is to take advice from experts, whether committee members who have specialized in a policy area or authorities who give testimony in hearings (Mugabe 2013). Despite such and related precautionary measures, uncertainty remains and its remnants sometimes lead to mistakes, both small and grand. For example, budget estimates and implementation plans made over a five-year period are undoubtedly going to lose accuracy over time. Members of Parliament cannot accurately predict which interpretations and actions government agencies and other implementers will take when reading and implementing policy (Brady and Volden 1998). Thus, while legislators and other actors may try to find out as much as they can about the policy consequences of various actions, they cannot be fully certain of the direct or indirect effects of a policy change (Mansbridge and Martin 2013). As a result, their (in)action will always involve taking some level of risk, in some cases resulting in policy gridlock.

Uncertainty of policy outcomes could either have a beneficial or adverse effect on the chances of a bill's passage, depending on perceptions of the status quo. When the public seems 
pleased with present policies, it may be difficult to pass new legislation (Binder 1999). Although the proposed policy could actually improve the status quo, legislators feel no pressure to take chances. In contrast to this case of uncertainty leading to inaction, at times politicians embrace an uncertain outcome. When the current policy is considered poor, the public perceives that things cannot get any worse. This paves the way for a string of new (and uncertain) policy proposals (Brady and Volden 1998). Thus, uncertainty over policy outcomes can either add to or relieve policy gridlock. When legislators are uncertain about the consequences of their actions, they may either take small steps or make no changes to current policy. However, when there is demand for immediate action, uncertainty could trigger a major policy change that would have been unacceptable to legislators had they been perfectly aware of the outcome.

The conceptual framework presented in Table 1 unpacks manifestation and causes of gridlocks at policy formulation, implementation and interaction levels, with the main focus of this article being the latter two.

Table 1: Conceptual framework on causes and types of policy gridlocks.

Source: Developed by authors, extending (Brady and Volden 1998).

\begin{tabular}{|l|l|l|}
\hline Gridlock level & Manifestation of gridlock & Causes \\
\hline Policy formulation & Delays/stagnation & Divided/fragmented legislature \\
& Ancoherence & Risk/Uncertainty \\
& Diversion & Information asymmetry \\
& & Fear of outcomes \\
\hline Policy implementation & Delays/stagnation & Uncertainty \\
\hline
\end{tabular}




\begin{tabular}{|c|c|c|}
\hline & $\begin{array}{l}\text { Poor outcomes } \\
\text { Alternative plans }\end{array}$ & $\begin{array}{l}\text { Resource and expertise } \\
\text { limitations } \\
\text { Fear of failure } \\
\text { Unintended consequences }\end{array}$ \\
\hline Policy interaction & $\begin{array}{l}\text { Contradictory bureaucratic } \\
\text { outcomes for different } \\
\text { policies }\end{array}$ & $\begin{array}{l}\text { Contradictory policy mixes on } \\
\text { interaction with existing or other } \\
\text { new policies } \\
\text { Destructive policies that } \\
\text { destabilize economic or social } \\
\text { equilibrium by affecting policies } \\
\text { in the immediate ecosystem. }\end{array}$ \\
\hline
\end{tabular}

The first level (formulation) largely pertains to the extent that gridlock at this level is the cause of gridlock at implementation and interaction levels. Building on Brady and Volden's (1998) concept of revolving gridlock in American politics, the framework guides this article to look at three broad sets of issues: first, how preferences at personal, legislative and implementing institution levels constrain or facilitate policy formulation, implementation and interaction with other policies; second, the impact of uncertainty in policy formulation, implementation and interaction; and third, the exogenous and endogenous factors affecting policy formulation, implementation and interaction processes. This article uses six case studies to illuminate through this framework the multi-dimensional and context-specific constellation of factors in these three areas, whether and how they lead to preservation of the status quo or some reversion that is not the status quo. 


\section{Case studies: Analysis and discussion}

This article draws from six independent case studies whose findings emerged from multimethod investigations. These case studies were brought together to illuminate and build a case for a further lens in the quest for deeper understandings of the causes, manifestations and amelioration options for 'policy gridlocks'. Contributors used cases that exhibit policy dilemmas characterized by incoherencies, conflicts and ambiguities as encountered in each of the contributor's primary areas of research. In addition, to ensure that the emerging policy gridlock characteristics are not a chance or coincidental artefact in specific sectors, the article sought and indeed examined cases from a variety of sectors. The contributors combined comprehensive content analysis of more than 25 policy documents passed in the 2000s and 2010s for all the sectors covered, with responses from more than fifteen in-depth interviews between 2012 and 2015 of policy-making elites and practitioners for each case study, making a combined total of more than 90 respondents.

A multiple case study approach was adopted in this quest to interrogate and discuss similarities and differences in multiple policy arenas. The multiple case study approach not only confers robustness (statistically or otherwise) to research conclusions compared to a single case study (Yin 2003), but was deemed particularly important for this article as the intention is to contribute to both theory and practice. Analysis and presentation of the data is through thematic analysis, based on broad themes derived from issues characterizing policy gridlock such as, but not limited to, policy inaction, policy incoherence and policy ambiguity. The following sections present each case study in detail, drawing out salient methodological issues for each case study as well as the unique policy gridlock scenarios in each case. 
Jurisdictional rivalries and turf wars: When a complex multi-agency regulatory system undermines itself

Kenya operates a multi-agency regulatory framework with different mandates shared amongst various ministries, regulatory authorities and state departments. While this multiagency regulatory framework has worked, albeit with challenges, having a multiplicity of laws, falling under different ministries applicable to a particular issue, leads to conflict over authority and mandates, especially when there are no clear command lines. Here we use two recent examples to highlight the likely consequences of policy incoherence and legal overlaps arising out of a complex regulatory structure with unclear coordination and command lines. The first case relates to December 2012, when the then Minister for Public Health invoked the Food, Drugs and Chemical Substances Act (Cap 254) to ban the importation of genetically modified foods into the country, citing threats to public health and safety. This was despite that fact that the country had in place a Biotechnology Policy of 2006; a Biosafety Act of 2009; and a fully functional National Biosafety Authority (NBA), though operating under a different ministry of the same government. In the second case, the High Court of Kenya, in a landmark ruling in April 2012, found that the Anti-Counterfeit Act of 2008 was partly unconstitutional in that while it focused on intellectual property rights protection, it was ambiguous and infringed on citizens' rights to access health products, particularly generic medicines. While the Anti-Counterfeit Act is the main instrument for fighting counterfeit and sub-standard medicine in Kenya, this mandate is also spread across three other sets of law - namely, the Pharmacy and Poisons Act; the Food, Drugs and Chemical Substances Act; and the Industrial Property Act - creating overlaps and duplication in the management of pharmacovigilance in Kenya. 


\section{Case study 1: Ban on importation of genetically modified organisms (GMO) foods}

In December 2012, The Minister for Public Health, invoking the provisions of the Food, Drugs and Chemical Substances Act (Cap 254), banned the importation of genetically modified organism (GMO) foods into Kenya. This ban followed a Cabinet decision and a directive to the relevant ministries, including the Ministry of Higher Education, Science and Technology under whose docket the NBA falls. Proponents of biotechnology have argued that this ban is an affront to the development of biotechnology in Kenya and runs counter to the national Biotechnology Policy (2006) and the Biosafety Act (2009). The fact that the Minister invoked a different law (Cap 254) and appeared to completely ignore the law dealing directly with biotechnology (and specifically, GMOs), i.e., the Biosafety Act has further created confusion as to the legality or otherwise of the said ban. Legal experts have also argued that since the said ban had not been officially gazetted, it lacked 'legal teeth' and cannot be enforced. The legal arguments notwithstanding, the ban was implemented with various government agencies confirming having received directives to enforce the ban.

According to the Hansard report (Wednesday, 19 December 2012), a question was raised in Kenyan Parliament by a private notice on the 'Ban on GMO Foods in Kenya' and the Minister for Public Health was asked, amongst other things, to explain, first, the criteria, credible scientific facts and evidence that informed the decision by the Government to ban the importation and use of GMO foods and products in the country; second, the effect of the ban on on-going biotechnology research in Kenya and the likely consequences on future food security; third, the involvement of the relevant government agencies, particularly the NBA, in 
the decision to ban GMO foods; and fourth, when the ban would be lifted. In her response, the Minister clarified that the ban was occasioned by 'the great concern on the safety of GMO foods'. The Minister further argued that 'where there is apprehension and uncertainty with regard to the safety of food products, precautionary measures to protect the health of the people must be undertaken'. She also informed the House that the ban would not affect ongoing biotechnology research in the country 'because the ban is on importation of GMO foods for human consumption or GMO foods that will eventually enter into the food chain and not biotechnology items used in research'. As regards the lifting of the ban, the Minister explained that

the Cabinet had directed that a taskforce be established to look at all available evidence and scientific research. This includes the latest study which emanates from French scientists which states that studies linking GMO maize to cancer must be taken seriously by the regulators.

The Minister further clarified that the temporary ban only covered foodstuffs and not other crops including fibres like sisal.

\section{Case study 2: Pharmacovigilance legal framework in Kenya}

Health products regulation is governed by the Pharmacy and Poisons Act (Cap. 244). The Act establishes the Pharmacy and Poisons Board (PPB) as the national medicine regulatory authority, under the Ministry of Health, and with a broad mandate 'to make better provision for the practice and profession of pharmacy and the trade in pharmaceutical products'. Besides PPB, at least three other sets of laws have provisions combating counterfeits, illicit 
trade, ensuring standards, creating institutions/agencies for enforcement, and claiming jurisdictions over pharmacovigilance activities. Pieces of legislation in this space include the Anti-Counterfeit Act (2008); The Food, Drugs and Chemical Substances Act, Cap. 254; and the Industrial Property Act (2001).

Section 3 of the Anti-Counterfeit Act, 2008, establishes the Anti-Counterfeit Agency (ACA). The Agency falls under the Ministry of Industrialization \& Enterprise Development, and it came into operation in June 2010. Even though in dealing with counterfeiting the emphasis in the ACA Act is on IP infringement, its provisions have relevance for public health concerns, especially as regards to: substandard medicines (lacking in quality, safety, and efficacy and may or may not include mislabelling and seen largely as a public health issue); counterfeits (deliberately and fraudulently mislabelled as to conceal identity/source and deceive consumers); and generics usually intended to be interchangeable with an innovator product that is manufactured without a licence from the innovator company and marketed after the expiry date of the patent or other exclusive rights.

While the fight against counterfeits is the thrust of the Anti-Counterfeit Act, it also fits in with the pharmacovigilance role of the PPB (under the Pharmacy and Poisons Act); the Food, Drugs and Chemical Substances Act also deals with the same issues when it prohibits sale of adulterated drugs and guards against deception and mislabelling. Issues of IP are further handled under the Industrial Property Act, 2001 (as amended to include trade and service marks). This legal overlap creates confusion and is likely to impede implementation of said laws. The key policy questions in such circumstances would be: which agency has the final 
authority when determining punitive/corrective action; and which laws are applicable in which circumstances?

\section{Lessons from the two case studies}

The two case studies presented highlight dilemmas arising from policy incoherence and legal overlaps. In the first case, riding on the powers granted to the Minister under the Food, Drugs and Chemical Substances Act, the ban on genetically modified food importation seems to have disregarded the fact that Kenya already had a biosafety regulatory system comprising a Biotechnology Policy (2006), biosafety law (2009) and a functional NBA. Despite legal arguments and lobbying against the ban, as of July 2017, the ban was still in force. In the second case, April 2012, the High Court of Kenya ruled that the Anti-Counterfeit Act, 2008, was partly unconstitutional - in that it infringed on citizen rights to access health products since it is ambiguous in defining counterfeit medicine and can hinder access to cheap generic medicine - and asked the Parliament to review the Act to be in line with the new constitution. The case shows the difficulty that ambiguity in the law can cause when patients' right to health and access to medicine run counter to the need to protect the intellectual property rights of inventors. These two cases highlight challenges resulting from cross-cutting functions and shared functions:

The 'institutional home' of agencies with cross-cutting functions matter when regulatory functions of an agency span across several ministries; such agencies should have the requisite convening power to oversee the other organs of government. For example, the NBA has mandate over biosafety management in the country. By its very nature, biotechnology (and 
biosafety) involves several ministries including agriculture, environment, health, industrialization and even defence. At the moment, NBA is domiciled in the ministry of Agriculture, Livestock and Fisheries. First, it is doubtful that the Ministry of Agriculture will have the convening power over the other ministries. Second, other aspects of biotechnology/biosafety are managed by the respective ministries, for example, the Ministry of Health claims jurisdiction over public health/safety as exemplified in the case when the then Minister for Public Health invoked the Food, Drugs and Chemical Substances Act (Cap 254) to ban importation of GMO food into Kenya and cited public health and safety as the basis for that ban. These examples show that overlaps in mandates, jurisdictions and laws can cause policy gridlocks at various stages of the policy process. In such cases of shared functions, there is need for a framework for consultation and coordination in order to ameliorate or minimize gridlocks.

In cases where functions are shared amongst different ministries, a framework for coordination and consultations to limit conflicts and enhance coherence should be created. This point is evident in both cases presented. In the first case, the Minister created a taskforce (drawing its membership from various ministries and regulatory agencies) to assess the evidence and advice government. Two issues arise here: first, there already existed government agencies and institutions whose key mandate it was to advise government on such matters, including the National Commission for Science, Technology and Innovation (NACOSTI), various regulatory agencies led by the NBA as well as non-governmental agencies such as the Kenya National Academy of Sciences (KNAS). That government did not consider advice from such agencies adequate raises issues of capacity and trust in national institutions. Second, that such a taskforce had to be created points to the lack of a coordinated framework 
that brings the various actors and agencies to the same table. An issue that spans several ministries (where each of these ministries claims a stake) should have a standing committee for regular consultations and coordination. In the second case, the different sets of laws have all created regulatory authorities with mandates touching on curbing counterfeiting and trade in sub-standard products. The issues span public health, trade, intellectual property and access to medicine. Yet, without a coordinating mechanism, the fight against counterfeits in Kenya remains a big challenge and the pharmacovigilance legal frameworks mired in confusion.

\section{Case study 3: The carbon tax story in South Africa}

As part of the global community, South Africa is engaged in measures seeking to manage the climate change problem. The country's latest grand indication to this end is the submission of an intended nationally determined contribution (INDC) document outlining South Africa's climate change adaptation and mitigation plans together with the related financing and investments requirements. South Africa articulates ambitious plans to reduce its greenhouse gas (GHG also called carbon) emissions, committing to cut emissions by 34 per cent from business as usual (BAU) by 2020, and by 42 per cent by 2025 (Department of Energy [DEA] 2015a). GHG emissions, particularly from anthropogenic activities, have been identified as a major contributor to global warming, which in turn ratchets climate change. Against this background, a cause for concern is that South Africa's emission-reduction targets represent a relative, not absolute, decline in emissions and are conditional on international support (Wolpe and Reddy 2015). The trajectory towards this relative decline is set to follow a 'peak, plateau, decline' (PPD) trajectory, with emission expected to peak by 2020, plateau until 2030 and begin to decline after 2030 (Wolpe and Reddy 2015: 1). This trajectory is cognisant of the 
associated climatic and economic implications of increasing GHG emission prior to a decline. On the climate side, it makes it difficult to ensure temperature increases are kept below $2^{\circ} \mathrm{C}$ above pre-industrial levels. More important is that there is a realization that a global average temperature increase of $2^{\circ} \mathrm{C}$ translates to up to $4^{\circ} \mathrm{C}$ for South Africa by the end of the century (DEA, 2015b). This could bring serious challenges to South Africa in the form of frequent and severe weather events such as droughts, floods and heat waves, all with devastating economic, social and environmental impacts.

At a glance, the PPD trajectory appears to be ill considered, particularly given that South Africa is Africa's biggest GHG emitter and is among the global 20 emitters (Department of National Treasury 2010). However, a closer examination reveals deep economic (and social) considerations. Most notable is that South Africa is a carbon-intensive economy based on electricity generated using a fossil fuel (coal) to power its manufacturing, services and mining industries (Department of National Treasury 2010). This historical status quo is reinforced by the coal abundance in the country as well as an established and locked in fossil fuel energy infrastructure. A sudden abandoning of this infrastructure will definitely lead to energy deficits with devastating economic and social consequences. Despite this South Africa is actively seeking to reduce its GHG emission. Efforts to this end include the quest to increase energy generation and use efficiencies and exploiting increased quantities of renewable energy (Department of National Treasury 2010). This approach is universally accepted. Disagreements arise around carbon taxation as an economic policy instrument for curbing GHG emissions but putting a price on the emissions (Nkabinde 2015). This has led to a carbon tax policy implementation gridlock despite government showing political will to employ this 
instrument by announcing intentions to introduce a phased-in emissions-based carbon tax in the 2012 National Budget.

The proposed tax regime gave exemption provisions to the highly trade-exposed and energyintensive industries, postponing but not halting the full imposition of carbon taxes (Alton et al. 2014). Despite this compromise sharp disagreements still remain, leading to delayed implementation. In general, proponents view the tax as stimuli that will spur advances in technologies exploiting renewable energy sources (Meltzer 2014). This will then decrease the carbon content of local manufactures and enhance their competitiveness in markets concerned about the carbon content of goods and services. In South Africa, opponents of the tax argue that the tax will reduce the country's competitiveness, particularly in export markets for minerals and metals (Alton et al. 2014). Since these sectors employ a vast number of people, there are concerns around job losses. In addition, there are concerns that carbon taxes will lead to higher energy prices particularly for the poor households. Such an impact on the poor would be undesirable given that the poor households have been found to be less carbon-intensive than middle-income households (Alton et al. 2014).

As the sixth year since the 2012 budget announcement draws to end, South Africa has not moved to effect this tax together with other measures such as the blending of liquid petroleum fuels with green fuels. The contestations and uncertainty are leading to government inertia despite the known dire consequences of failure to mitigate climate change. The immediate economic and social ramifications (uncertain to an extent) of a carbon tax together with the strong voice of an organized anti-carbon tax lobbyist is exacerbating the inertia. Despite this, South Africa firmly maintains that it is committed to the ideals of 
sustainable development that seek to ensure that present economic, social and environmental practices do not adversely impact the livelihoods of future generations. How this gridlock will be unlocked remains an issue of great interest to policy and sustainable development scholars, practitioners and other stakeholders.

\section{Case study 4: Financing of local pharmaceutical manufacture in Africa}

Financing local drug manufacture occurs within complex national policy and practice contexts. In as much as local pharmaceutical firms can develop finance, investment, production, engineering, management and linkage capabilities for economic viability, they are still subject to the vagaries of policy formulation, implementation and interaction downsides. This case study is based on work carried out between 2012 and 2014 using multiple methods, including semi-structured interviews and desk research, for gathering data to understand how manufacturing of antiretroviral drugs was being financed in Zimbabwe. A total of fifteen respondents were interviewed, drawn from Zimbabwean commercial banks, an African regional development bank and three major pharmaceutical manufacturing firms operating in Zimbabwe. The broad objective of the study was to understand how antiretroviral drugs manufacture was financed in Zimbabwe and the impact of this on technological capability upgrading and innovation. How policy gridlocks impacted financing local production and access to medicines in the public health system was a major component of that study. The rest of this section discusses policy gridlocks as exemplified by challenges faced by firms and their impact on: costs of manufacturing; financing costs; and compliance costs. The study found that one aspect of policy gridlock arose when policy failure at national level forced unplanned and uncoordinated policy and practice (operational) responses at firm level and occasionally regulatory responses at supranational level, resulting in congested 
policy spaces (Banda 2013). The first example of policy gridlock arising from such supranational responses is the World Health Organisation (WHO) prequalification approach for manufacturers and suppliers of pharmaceutical products.

When the HIV/AIDS pandemic needed a global medicines-supply response, there was a general feeling that local regulatory agencies were weak and WHO pre-qualification became a requisite for firms to access international tenders. Firms responded to this supranational policy and invested in meeting the requirements anticipating sales from international tenders. One of the firms in the study went for over a year without getting an international tender, as they alleged that the tender prices were not sustainable. The cost of maintaining the WHO prequalified facility was met by local and regional sales and not international sales. In addition, the firm had to comply with local and export country regulatory requirements. Policy gridlocks arose from the need for multiple compliance with local, regional and supranational regulatory regimes. At policy interaction level the gridlock imposes higher compliance costs on local drug manufacture.

The second example of policy gridlock emanates from uncoordinated public health, finance, trade and industrial development policy formulation, implementation and interaction. From a public health perspective, imported ARVs are not subject to duty or taxes, whilst for local manufacture, although ARV active pharmaceutical ingredients (APIs) are exempt from duty, other raw materials such as excipients and packaging that can be used to make other drugs and spare parts are not exempt (Banda 2013). Although some of the inputs qualify for rebates, the firms argued that the process of claiming the rebate was long and cumbersome it was not worth engaging with the revenue authorities on that front. Thus, a public health policy 
initiative to make medicines available cheaply that is not aligned with the finance policy that levies taxes and duty on raw materials and spare parts counteracts industrial development policy, making locally manufactured drugs less competitive compared to imported (duty free) finished drugs.

From a financing perspective, at firm level, bank credit policies, underwriting standards, capital utilization strategies and risk-reward remuneration policies determine credit availability for the pharmaceutical industry. It was found that banks favour short-term credit policies and lending technologies and prefer non-funded income over funded income (risk lending): this is implicit credit rationing. Although national policy on trade and industry revival through the Zimbabwe Economic Trade Revival Facility (ZETRAF) sought long-term finance for industry, working capital finance was prohibitively high, making local production uncompetitive (Banda 2013).

\section{Case study 5: Health delivery systems: gridlocked by design?}

On-going work by Mugwagwa and others on health system strengthening argues that the complexity of health systems seems to render them inherently gridlocked (Mugwagwa 2015a; Mugwagwa et al. 2015). From an open systems theory perspective, health systems, with intricate overlapping layers and loops ranging from the individual to the global, can aptly be ranked among those that are selectively more open than other systems (Scott 2002). Increasingly, an individual's health challenges and treatment needs in any part of the world are becoming soluble only within an interconnected labyrinth of supplies of different components of the health remedies (Mugwagwa 2015a). This globalized network of actors and actions has in many places replaced locally available solutions, handicapping and 
strengthening alike policy and operational systems and the ability of individuals to readily find solutions on their own. Through case studies in South Africa and Zimbabwe investigating, among others, decision-making and resource deployment in health systems (Mugwagwa 2015b) and across SSA on harmonization of medicines regulatory systems (Mugwagwa 2015a), one of many policy and operational gridlocks in and around the health arena has been seen to be on how best the concern and actions of those with the greatest influence can be made to align with the greatest concerns of those with the least influence.

The studies on health system strengthening have been multi-method inquiries encompassing questionnaire-led interviews, literature reviews, participation in and observation of relevant policy and practice processes mainly in Africa between 2012 and 2015. Actors who served as respondents include health practitioners, pharmaceutical industry representatives, donors/development partners, academics and researchers working on different aspects of health innovation and health systems, policy-makers, civil society actors, regulators and users of health systems. As envisaged, a diverse range of findings emerged from these processes on how best to strengthen and sustain health delivery systems in low- and middle-income countries. Health systems are complex systems with many parts that operate at different levels. In addition to patients, families and communities, Ministries of Health, health providers, health services organizations, pharmaceutical companies, health financing bodies and other organizations play important roles. The interconnections of the health system can be viewed as the functions and roles played by these parts. Across different countries, these functions include oversight (e.g., policy-making, regulation), health service provision (e.g., clinical services, health promotion), financing and managing resources (e.g., pharmaceuticals, medical equipment and information). Describing the parts, interconnections and purpose, 
Roemer (1993) defined a health system as 'the combination of resources, organization, financing and management that culminate in the delivery of health services to the population'. The World Health Organization (2000) redefined the main purpose in its definition of a health system as 'all activities whose primary purpose is to promote, restore, and maintain health'. In recent years, the definition of 'purpose' has been further extended to include the prevention of household poverty due to illness. The definitions alone reveal much complex, yet, in addition, there are many other factors outside the health system that influence people's health, such as poverty, education, infrastructure and the broader social and political environment, making interpretation and implementation of health policies a complex challenge.

The complexity of health delivery systems comes to the fore even further when the components and connections are unpacked to reveal asymmetries in financial, political and intellectual power, interests and motivations for involvement in the health system as well as the burden and urgency of the health challenges faced. For example, it was observed in South Africa and Zimbabwe that due to limited financial resources and preoccupation with other survival chores, there is limited influence on the part of communities, especially rural communities, to challenge or reshape the predominantly top-down and state-centred health delivery models, which may not be adequately serving the needs of the communities. People have accepted to travel long distances (up to $20 \mathrm{~km}$ in some rural areas in both countries) or wait long periods to get access to health facilities; or resorted to using alternative medical systems such as traditional healers or other home remedies. On the other hand, inadequacies of financial, human and infrastructural resources are perennial changes for many African governments, resulting in them always having to seek resources from multiple sources, 
including donors, private sector and civil society actors, a situation that not only comes with challenges of how to maintain standards and accountability within the system, but also the reality of misaligned priorities between those of governments as custodians of national health delivery and the providers of resources. Further, in cases where resources provided by the additional sources are inadequate, the dilemma of deciding and prioritizing where to spend them emerge. Resources provided with all the good intentions may also have disruptive effects on the broader system because of shortages elsewhere, for example, the multipledonor Health Transition Fund (for maternal and child health) in Zimbabwe has been accused of having 'resulted in other facets of the health system suffering from reduced external and internal funding attention as well as diminished policy attention' (Mugwagwa et al. 2017).

On strengthening health delivery systems through cross-country coordination of medicines regulatory systems, findings of a two-year study by Mugwagwa revealed that implementation of the harmonization agenda is fraught with many challenges inherent in and transcending cross-country cooperation in general and health systems in particular (2015a). It is clear that there are numerous health delivery problems that countries cannot solve unilaterally due to realities attributable to globalization and rapidly advancing technological frontiers, for example, the ability to ensure adequate, safe, efficacious and affordable medical products. Yet even with these imperatives, delivering harmonization of medicines regulatory systems faces multiple hurdles ranging from different pressures faced by countries to embrace this policy option, 'prisoners' dilemmas' from information asymmetries on what each country brings to and takes away from the harmonization agenda, to sheer hegemonic rent-seeking behaviour from some of the countries as they try to impose their national policy positions on their regional partners. Some respondents also questioned whether the cost of policy-making 
and policy oversight around this issue would be justified and desirable given that regulators in most countries were already overstretched and struggling to effectively implement existing policies. Related to this was that for the harmonization agenda, and other health policy arenas, there was lack of continuous 'leadership and followership' (Mugwagwa 2015a) on the given issues, with these being intermittent in most situations, leading to inconsistent processes, actor coalitions, policy targets and policy outputs. This, however, is a reality of many policy arenas, which is further exacerbated by shortages of finances, personnel and other resources resulting in absence of a standby cadre of policy entrepreneurs or others who are easily mobilizable when issues to address arise (Scott 2002; Ojha et al. 2013).

While uncertainty over political and regulatory consequences are a major factor in the gridlock around harmonization of medicines regulatory systems, findings from the case study on health spending indicate that financial and human resource inadequacies are the major causes of gridlocks. Inadequate resources result in policies not being implemented, or being implemented only partially, impacting various facets of the health delivery system directly or indirectly.

\section{Case study 6: The interface between oil, policy and economic development in Angola}

Recent work by Teka (2012) exemplifies the emergence and persistence of resource-led policy gridlocks in the agenda for development in Angola. Data collected through interviews with oil sector stakeholders between October 2009 and January 2012, looking at industrial linkages in the Angolan oil and gas industry, revealed gridlocks between macro- and meso-levels policy processes. While the literature places gridlock causality primarily on impasses incurred in the process of policy-making, which subsequently affect implementation (VanSickle-Ward 2014), 
findings from the Angolan case study are that in the experience of developing countries, gridlock causes lie equally in the quality of the policies that emerge from such processes. This in turn is intricately linked to the pre- and post-independence political landscapes of the countries. In the case of Angola, a post-independence landscape dominated by one party.

This dominance has not only rendered pluralism and rationalism less relevant, but has also resulted in, and been sustained by, diminished roles of linkage institutions such as non-state actors and the private sector in political and policy processes. As governance actors, these institutions would play crucial roles in enhancing the work of key government agencies with mandates in the oil sector, through understanding structures and institutional processes of policy-making in the country, and enabling identification of and mediation over potential impasse factors (Ojha et al. 2013). Important government departments in the Angolan oil sector include the ministries of planning, economy, industry, education, science and technology, and petroleum. The first five ministries are responsible for the national development and industrialization strategies, while the last ministry is responsible for the diversification and beneficiation strategies in the oil and gas sector (Teka 2012). Between these various departments are various macro-, meso- and micro-level interfaces where gridlocks can (and do) occur due to tussles and clashes over mandates, interests and political turf. Our contention is that minimization or amelioration of gridlocks in these spaces requires different sets of actors whose mandates are different yet complementary to those of government departments.

\section{Summary}

Drawing from different disciplines and evidence gathered in different national and sectoral settings, the different cases studies illuminate a number of overlapping causes and 
manifestations of policy gridlocks and possible options for minimizing or ameliorating the gridlocks. Table 2 below summarizes these different issues, guided by the conceptual framework presented in Table 1. 
Table 2: Manifestation, causes and options for amelioration of policy gridlocks in selected sectors of some African countries.

Source: Table created by authors summarizing findings from case studies. 


\begin{tabular}{|c|c|c|}
\hline Manifestation & Causes & How to resolve them \\
\hline Policy inaction & $\begin{array}{l}\text { Institutional resource and capacity constraints (all } \\
\text { CSs) } \\
\text { Fear of negative policy impacts (CS1 and CS3) } \\
\text { Uncertainty over policy outcomes and impact (all } \\
\text { CSs) } \\
\text { pluralistic executive (all CSs) } \\
\text { Uncertainty about stakeholder reactions (CS1 \& } \\
\text { CS3) }\end{array}$ & $\begin{array}{l}\text { Identify links between } \\
\text { profile/level of policy } \\
\text { and tendency for } \\
\text { inaction, ambiguity or } \\
\text { incoherence } \\
\text { Evidence based policy } \\
\text { formulation approaches } \\
\text { Early, consistent and } \\
\text { effective engagement of } \\
\text { stakeholders } \\
\text { inaction }\end{array}$ \\
\hline $\begin{array}{l}\text { Policy } \\
\text { ambiguity }\end{array}$ & $\begin{array}{l}\text { Multiple and overlapping policy mandates (CS1, } 3 \\
\text { and 6) }\end{array}$ & $\begin{array}{l}\text { Identify, understand and } \\
\text { address cause of } \\
\text { ambiguity, bearing in }\end{array}$ \\
\hline
\end{tabular}




\begin{tabular}{|c|c|c|}
\hline & $\begin{array}{l}\text { Policy misinterpretation (CS1) } \\
\text { Conflation of ideas (CS2) } \\
\text { Policy complexity and detail (CS3, } 4 \text { and } 5 \text { ) } \\
\text { Issue controversy (CS1) } \\
\text { Historical and contemporary contextual dynamics } \\
\text { (all CSs) }\end{array}$ & $\begin{array}{l}\text { mind that in some cases, } \\
\text { ambiguity serves as a } \\
\text { vehicle for compromise } \\
\text { when key participants } \\
\text { disagree over details }\end{array}$ \\
\hline $\begin{array}{l}\text { Policy } \\
\text { incoherence }\end{array}$ & $\begin{array}{l}\text { Conflicting policy objectives (all CSs) } \\
\text { Policy misalignment (all CSs) } \\
\text { Conflicting implementation arrangements (all CSs) } \\
\text { Historical and contemporary contextual dynamics } \\
\text { (all CSs) }\end{array}$ & $\begin{array}{l}\text { Identify drivers and } \\
\text { sustainers of policy } \\
\text { incoherence }\end{array}$ \\
\hline
\end{tabular}

The similarity of causes and manifestations of gridlocks presented by the different cases show that while context plays a key role in shaping policy processes, including implementation, there are features transcending policy processes and arenas that lead to wasted resources and poorer outcomes for stakeholders if left unchecked. Unpacking policy gridlocks presents a system-wide opportunity for identifying and addressing such features through various 
means, including, but not limited to, removal of information asymmetries across different areas affected by particular policies. This is as much a role for policy-makers, with respect to ensuring that there is coherence of policy objectives and implementation plans, as much as it is for actors responsible for the day-to-day implementation of the policies, who should flag up and resolve gridlocks within the context of coherent sectoral and national policy objectives.

\section{Conclusions}

Seeking to make a multi-disciplinary contribution towards unpacking and deepening understandings of policy formulation and implementation processes in Africa, this article has used six different and independent case studies to deploy and interrogate the concept of policy gridlocks, focusing particularly on how policy gridlocks emerge, what happens in these gridlocks and what lessons can be inherited by future and allied policy processes. The case studies, covering horticulture, mining, pharmaceutical production, science, technology and innovation, environment and health systems, identified and discussed a number of causes and sustainers of policy gridlocks, ranging from policy multiplicity and overlapping mandates; inconsistent policy targets and actor coalitions; variable policy pressures and policy incoherence; clashes among sectoral objectives; intra- and inter-national policy divergences; disconnects between political will and action; inertia caused by unfulfilled promises, contestations, uncertainty and lack of quantification of cost of policy inefficiencies; tensions between long-term and immediate policy needs; complexity and fluidity of policy arenas; information asymmetries; to lack of financial, human resource and other critical capacities for developing, implementing and monitoring policies. While there are salient contextual realities leading to these gridlocks for each case, it is clear from the cases that there are individual and 
collective policy levers/opportunities for amelioration of the gridlocks in each case or in other cases.

This article has demonstrated through the case studies that policy gridlocks not only diminish the quantity and quality of policy outputs, but also strain relationships between different actors in the policy terrain, affecting both current and future policy processes. To redeem these relationships, and a key factor in minimizing or ameliorating gridlocks, regulators and practitioner stakeholders need to quantify and more directly feel the cost of their decisions, or lack thereof, while scholars must continue to search for institutional means to preventing gridlock, and this includes mitigating the negative effects of unnecessary polarization. To this end, the authors envisage further work to focus on specific instances of policy and practiceled resolution of gridlocks, including possibilities of having in-built mechanisms for avoiding gridlocks in the first place. This would be a contribution to growing theoretical and empirical work around 'smart governance' and 'agile governance'.

In the final analysis, this article concludes that limits in financial resources, technical expertise and legislative capacity are the more pervasive and persistent drivers of policy implementation gridlocks that should be confronted than fragmentation of policy interests which is a contextual reality at all times in all policy arenas globally. Policy arenas in Africa, as exemplified by our case studies, face perennial and seemingly intractable constraints as a result, among others, of weak knowledge bases, inefficient collaboration and poor consultation and involvement of key stakeholders. These constraints in turn result from and/or exacerbate implementation gridlocks. While the constraints are not unique to African countries, the resultant development inertia in this region calls for innovative ways of 
addressing the causes and consequences of these gridlocks to be deployed if sustainable and inclusive development targets are to be met. Engagement by scholars and policy practitioners with the existence, causes and consequences of policy gridlocks, as argued in this article, will go a long way towards reshaping policy formulation and implementation in particular and development agendas more broadly.

\section{Acknowledgements}

In addition to our various employers, as authors we wish to acknowledge the Open University's Innovation, Knowledge and Development (IKD) Research Centre for the SeedCorn funding which enabled exploration of this idea. Julius Mugwagwa also acknowledges the ESRC Future Research Leaders Funding Scheme for grant number ES/K001442/1 which allowed further development and conclusion of the idea and manuscript.

\section{References}

Alton, T., Channing A., Davies, R., Hartley, F., Makrelov, K., Thorlow, J. and Ubogu, D. (2014), 'Introducing carbon taxes in South Africa', Applied Energy, 116, pp. 344-54.

Banda, Geoffrey (2013), 'Finance as a "forgotten technological capability" for promoting African local pharmaceutical manufacture', International Journal of Technology Management and Sustainable Development, 12:2 pp. 117-35.

Barber, Michael and McCarty, Nolan (2013), 'Causes and consequences of polarization' pp 1954, in Mansbridge, J. and Martin, C. J. (2013) (ed) Task Force on Negotiating Agreement in 
Politics, by American Political Science Association, American Political Science Association. Washington DC

Binder, Sarah A. (1999), 'The dynamics of legislative gridlock, 1947-96', American Political Science Review, 93:3, pp. 519-33.

Brady, D. W. and Volden, C. (1998), Revolving Gridlock: Politics and Policy from Carter to Clinton, Boulder, CO: Westview Press.

Department of Energy [DEA] (2015a), 'State of renewable energy in South Africa', Republic of South Africa, http://www.gov.za/sites/www.gov.za/files/State\%20of\%20Renewable\%20Energy\%20in\%20 South\%20Africa_s.pdf. Accessed 1 November 2017.

(2015b), 'South Africa's Intended Nationally Determined Contribution (INDC)', discussion document, Republic of South Africa, https://www.environment.gov.za/sites/default/files/docs/sanational determinedcontributi on.pdf. Accessed 2 November 2017.

Department of National Treasury (2010), 'Reducing greenhouse gas emissions: The carbon tax option December 2010', Republic of South Africa, http://www.treasury.gov.za/public\%20comments/Discussion\%20Paper\%20Carbon\%20Taxe s\%2081210.pdf. Accessed 2 November 2017. 
Mansbridge, J. and Martin, C. J. (2013) (ed), Negotiating Agreement in Politics, American Political Studies Association Task Force Report, American Political Studies Association Task Force. Washington DC

Mayhew, D. R. (2005), Divided We Govern: Party Control, Lawmaking, and Investigations, 1946-2002, 2nd ed., Yale University Press. New Haven.

Meltzer, J. (2014), 'A carbon tax as a driver of green technology innovation and the implications for international trade', http://www.felj.org/sites/default/files/docs/elj351/1445-Meltzer Final\%205.13.14.pdf. Accessed 3 November 2017.

Mugabe J (2013). Accelerating health research for Africa's development: An assessment of the effectiveness of national policies in eastern and southern Africa. Policy Brief, University of Pretoria, South Africa.

Mugwagwa, Julius (2015a), 'Innovating for public health: Towards harmonized medicines regulatory systems in Africa', International Journal of Technology Management \& Sustainable Development, 14:3, pp. 163-77.

(2015b), 'Innovative spending in health: What should money be spent on to make global health innovations more effective in developing countries?', BMJ Open, 5 (Suppl. 1; article no. 057). 
Mugwagwa, J., Chinyadza, J., and Banda, G., (2017). Private sector participation in health care in Zimbabwe: what's the value added? Journal of Healthcare Communications, Vol. 2 No. 2:10. pp 1- 9, DOI: 10.4172/2472-1654.100050.

Mugwagwa, Julius, Edwards, Daniel and Haan, Sylvia de (2015), 'Assessing the implementation and influence of policies that support research and innovation systems for health: The cases of Mozambique, Senegal, and Tanzania', Health Research Policy and Systems, 13:21, pp 1-7.

Nkabinde, S. (2015), 'Could carbon tax be good for SA economy?', http://www.moneyweb.co.za/uncategorized/carbon-tax-goodeconomy/. Accessed 2 November 2017.

Reilly, Ben (2002), 'Electoral systems for divided societies', Journal of Democracy, 13:2, pp. $156-70$.

Roemer, M (1993). National health systems of the world. New York. Oxford University Press

Scott, W. R. (2002), Organizations: Rational, Natural, and Open Systems, Upper Saddle River, NJ: Prentice Hall.

Teka, Zeferino (2012), 'Linkages to manufacturing in the resource sector: The case of the Angolan oil and gas industry', Resources Policy, 37 (4), pp. 461-67. 
UNEP (2016), Resource Efficiency: Potential and Economic Implications (eds P. Ekins et al.), report, International Resource Panel, http://pure.iiasa.ac.at/id/eprint/13813/1/Resource Efficiency Potential and Economic Implications; summary for PolicyMakersResource-Eff-irp-Ir.pdf.pdf. Kenya: UNEP, Accessed 10 August 2018.

VanSickle-Ward, R. (2014), The Devil Is in the Details: Understanding the Causes of Policy Specificity and Ambiguity, Albany: State University of New York.

Wolpe Peta and Reddy, Yachika (2015), 'The contribution of low-carbon cities to South Africa's greenhouse gas emissions reduction goals', briefing on urban energy use and greenhouse gas emissions,

https://www.seiinternational.org/mediamanager/documents/Publications/Climate/Citieslow-carbon-future-2015-South-Africa-briefing.pdf. Accessed 1 November 2017.

World Health Organisation (2000). The World Health Report 2000: Health Systems: Improving Performance. Geneva, Switzerland: WHO

Yin, R. K. (2003), Case Study Research: Design and Methods, California, London and New Delhi: Sage Publications.

\section{Contributor details}

Dr Julius Mugwagwa is a lecturer in innovation and development at University College London, Department of Science, Technology, Engineering and Public Policy (UCL STEaPP). He 
has worked in veterinary research, pharmaceutical R\&D and quality assurance and harmonization of medicines regulatory systems in Africa. He is an accomplished scholar and published author in the areas of health innovation and health system strengthening, buttressed by his research and teaching interests in the governance and development implications of technologies and innovations.

Dr Geoffrey Banda is a lecturer at the Innogen Institute within Science, Technology and Innovation Studies (STIS) at the University of Edinburgh. With extensive experience in quality assurance as well as the finance and banking sector, his recent research endeavours have focused on innovation, financing and development of the pharmaceutical sector in Africa; business models, value chains and innovation ecosystems for commercialization of stem cell therapies; and strategies for sustainable health sector innovation in Africa.

Dr Maurice Ochieng Bolo is the Founding Director of the Nairobi-based Science, Technology and Innovation (STI) Policy think-tank - The Scinnovent Centre. He has published widely on issues of Innovation, Technology, Policy and Development focusing on Africa.

Dr Susan Mbula Kilonzo holds a doctorate in the sociology of religion. She is a senior lecturer in the School of Arts and Social Sciences at Maseno University, Kenya. She is a multidisciplinary researcher in the fields of sociology, community development, peace and security, higher education, and, HIV and AIDS in Africa.

Prof Clapperton Chakanetsa Mavhunga is an associate professor of Science, Technology and Society (STS) at Massachusetts Institute of Technology (MIT), Program in Science, 
Technology and Society. His professional interests lie in the history, theory, and practice of science, technology, innovation and entrepreneurship in the international context, with a focus on Africa.

Dr Vuyo Mjimba is a development studies scholar with research interests in sustainable industrialization, focusing particularly on global value chains, climate change and innovation. He has experience of working with research teams in both public and private sectors. Currently he works for the Africa Institute of South Africa in the Human Sciences Research Council.

Olivia Muza is a development economist and consultant based in Harare, Zimbabwe. She has research and consultancy interests in environment, agriculture, water, food security and nutrition.

Dr Zeferino Teka is a Governance Programme Specialist United Nations Development Programme (UNDP) in Luanda, Angola. He holds a Ph.D. in Development Economics from the Open University, UK, and has published widely on global value chains and mineral commodities in Africa.

Contact:

Julius Mugwagwa. UCL, Department of Science, Technology, Engineering and Public Policy (UCL STEaPP), 36-38 Fitzroy Square (2nd Floor), London, W1T 6EY, UK. E-mail Address: j.mugwagwa@ucl.ac.uk https://orcid.org/ 0000-0003-1570-1910 
Geoffrey Banda, Innogen Institute, University of Edinburgh, 2.03 Old Surgeons Hall, High School Yards, Edinburgh EH1 1LZ, UK.

E-mail address: Geoffrey.banda@ed.ac.uk

https://orcid.org/

Maurice Ochieng Bolo, The Scinnovent Centre, Gate 123, Mountain View Estate, P.O. Box 52486, 00100, Nairobi, Kenya.

E-mail address: bolo@scinnovent.org

https://orcid.org/0000-0003-0243-6804

Susan Mbula Kilonzo, Department of Religion and Philosophy, Maseno University, Private Bag, Maseno, Kenya.

E-mail: mbusupa@yahoo.com

https://orcid.org/

Clapperton Chakanetsa Mavhunga, Building E51-163, Massachusetts Institute of Technology, 77 Massachusetts Avenue, Cambridge, MA 02139, USA.

E-mail address: mavhunga@mit.edu

https://orcid.org/

Vuyo Mjimba, HSRC Building, 134 Pretorious Street, Bag X41, Pretoria, South Africa.

E-mail address: vmjimba@hsrc.ac.za

https://orcid.org/0000-0003-1058-3986 
Olivia Muza

E-mail address: oliviamuza@gmail.com

https://orcid.org/ 0000-0002-7821-9649

Zeferino Teka

E-mail address: zeferinote7@hotmail.com

https://orcid.org/ 